\title{
Options under annuity, a choice of values - The Indian experience
}

Received: (in revised form): 19th March, 2008

\section{V.N.S. Pillai}

is a faculty member at LIC Southern Zonal Training Centre in Chennai (Madras), teaching economics and law of life insurance and pensions. His contributions to education and research in life insurance and pensions are enormous and he is associated with many universities regarding this. He is the recipient of several awards and recognition, and the latest addition to this list was the conferring of Best Business Academic of the Year 2006 by the Indian Commerce Association. The findings, interpretations and conclusions expressed in this article are entirely those of the author. They do not necessarily represent the view of the Life Insurance Corporation of India.

\begin{abstract}
Annuity plans are purchased based on the returns they provide on funds invested. Yet the options given under annuity plans need not be exercised by annuitants on the basis of returns they are more influenced by societal values.
\end{abstract}

Pensions (2008) 13, 49-53. doi:10.1057/pm.2008.7

Keywords: life annuity, annuity certain, ROC, options, societal values, family protection

The major pensions/annuities available to government servants and other workers in India are(i) central government pensions, (ii) state government pensions, (iii) public sector pensions, (iv) provident fund-linked pensions, and (v) pensions/annuities paid by the life insurance companies. There is financial assistance from the government, both central and state, in the form of widow pension, destitute pension, etc, where the pension paid is too small, supporting subsistence. In the first four of the above, pensions are paid to the pensioner until his death, and a family pension at a lower rate is paid to the spouse of the deceased until the spouse's death and thereafter in some cases to the youngest son/daughter till he/she attains the age of majority. This system goes hand in hand with Indian culture, which makes every man provide for his spouse and children during his lifetime and bequeath his property to his dependants on his death. The only option available to a pensioner is to take a commuted value of the pension at the time of commencement of

Correspondence: V.N.S. Pillai, LIC Southern Zonal Training Centre, Prithvipakkam, Ambattur, Chennai 600053, India.

Tel: +91044 26860676 ext. 303;

Fax: +91044 26860253;

E-mails: vns.pillai@licindia.com; sreekaran@sify.com pensions. Commutation is allowed at the rate of one-third of the pension.

Life insurance companies in India allow several options to pensioners/annuitants other than the commutation of pension. These options are of three types, viz. (i) option to decide the age at which annuity/pension payments shall commence, (ii) option to decide the mode of receipt of pension/annuity, viz. annual, half yearly, quarterly or monthly, and (iii) option to decide the type of pension/annuity to be received.

The following are the major types of annuity/ pension options:

1. Pension for life.

2. Pension for five years certain and thereafter for life.

3. Pension for ten years certain and thereafter for life.

4. Pension for 15 years certain and thereafter for life.

5. Pension for 20 years certain and thereafter for life.

6. Joint life pensions, covering pensioner and spouse.

7. Pensions, increasing at the rate of 3 per cent every year, for life.

8. Pensions for life, with return of capital (ROC) on death to nominee. 
The pension/annuity available under each of these options varies widely for obvious reasons. Table 1 shows the annuity available under various options at current rates.

The annuity rates decrease as the guarantees increase as shown in Figure 1. Series 1 represents the options and series 2 represents the rates of annuity. The cost for moving from no guarantee to full guarantee is INR22.40 [93.50 (-) 71.10], 24 per cent of the life annuity rate when the rate of return is 9.35 per cent. It is also seen that the cost of guarantee increases inversely to the return on investment on annuity policies reflected through the annual rates of annuity (see Table 2). It could also be seen (from the insurer's angle) as the premium that accumulates to the purchase price in a period of 20 years, and from the perspective of the customer, the premium paid for obtaining a guarantee for ROC to his nominees.

A study was conducted on people's choices on annuity options by interviewing 105 educated people and asking them to answer a questionnaire on the subject to determine whether rate of annuity (rate of return on investment) was a major factor in deciding annuity options. Some of them were eligible for other pensions such as

Table 1: Annuity available under various options at current rates

\begin{tabular}{lllll}
\hline Options as given above: & $(1)$ & $(2)$ & $(3)$ & $(4)$ \\
Annuity payable yearly: & 93.50 & 92.60 & 90.60 & 87.90 \\
& & & & \\
Options as given above: & $(5)$ & $(6)$ & $(7)$ & $(8)$ \\
Annuity payable yearly: & 84.80 & 80.30 & 75.30 & 71.10 \\
\hline
\end{tabular}

Pension table for New Jeevan Akshay VI (New Jeevan Akshay $\mathrm{VI}$ is an immediate annuity plan of the Life Insurance Corporation of India.) is given here in Indian rupees (INR) for a purchase price of INR 1,000/-. Age at which annuity is to commence is assumed to be 60 years. government pensions/public sector pensions whereas others were not. Those interviewed were in the age group of 30-40 years. Their preferences have futuristic value. They were also asked to list out their reasoning for choosing a particular option. The response of the group was as follows:

- Preference for life pension/annuity: Five per cent.

- Preference for pension/annuity with some type of guarantee: 11 per cent.

- Preference for pension/annuity with provision for ROC: 84 per cent.

This shows a trend inversely proportional to rate of return. Or it may be better explained as a preference to guaranteed incomes.

Table 3 shows statistics pertaining to Group Superannuation policyholders' preferences on various types of annuities. Figure 2 shows the figures of Table 3 in percentages.

Similarly the figures pertaining to annuitants of individual pension policies for the past 20 years

Table 2: $\mathrm{ROI}$ and cost of guarantee ${ }^{\mathrm{a}}$

\begin{tabular}{lll}
\hline Year & $\begin{array}{l}\text { ROI as reflected } \\
\text { through the annual } \\
\text { rates of annuity (\%) }\end{array}$ & $\begin{array}{l}\text { Cost of } \\
\text { guarantee as \% } \\
\text { of life pension }\end{array}$ \\
\hline $2001-2002$ & 9.50 & 25.36 \\
$2003-2004$ & 7.78 & 37.66 \\
$2004-2005$ & 8.56 & 31.54 \\
$2005-2006$ & 8.70 & 27.35 \\
$2006-2007$ & 9.20 & 24.81 \\
$2007-2008$ & 9.35 & 23.95 \\
\hline
\end{tabular}

${ }^{\mathrm{a}} \mathrm{ROI}$ (return on investment) represents the rates of life annuities of various New Jeevan Akshaya plans introduced each year. Cost of guarantee represents the difference between life annuity and 'Annuity with return of capital expressed as a per cent of life annuity rates.

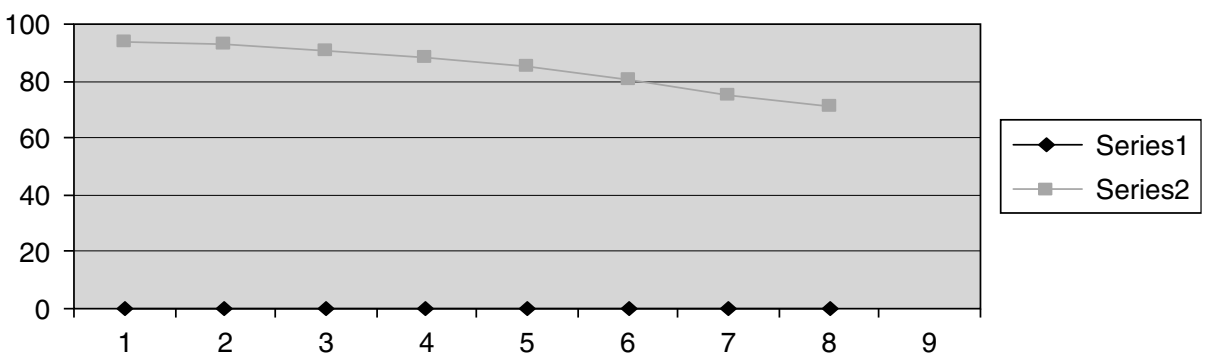

Figure 1: Decline in annuity rates as guarantees increase 
Table 3: Group Superannuation policyholders' preferences on various types of annuities

\begin{tabular}{lrrrr}
\hline Year & \multicolumn{1}{l}{ Life } & \multicolumn{1}{l}{ C } & \multicolumn{1}{l}{ Total } \\
\hline $1997-1998$ & 348 & 1,644 & 38 & 2,030 \\
$1998-1999$ & 269 & 2,276 & 43 & 2,588 \\
$1999-2000$ & 273 & 2,272 & 43 & 2,588 \\
$2000-2001$ & 302 & 2,733 & 128 & 3,163 \\
$2001-2002$ & 359 & 2,295 & 50 & 2,704 \\
$2002-2003$ & 529 & 4,268 & 74 & 4,871 \\
$2003-2004$ & 784 & 3,351 & 58 & 4,193 \\
$2004-2005$ & 685 & 3,437 & 54 & 4,176 \\
$2005-2006$ & 288 & 2,252 & 58 & 2,598 \\
$2006-2007$ & 280 & 2,621 & 49 & 2,950 \\
$2007-2008$ & 160 & 1,645 & 17 & 1,822 \\
Total & 5,677 & 27,394 & 612 & 33,683 \\
\hline
\end{tabular}

LIFE=Number of persons who have opted for life pensions in each year; $R=$ number of persons who have opted for pension with a provision for return of capital (purchase price) to the nominee. $\mathrm{C}=$ number of persons who have opted for pensions with guarantee for a certain number of years. $C$ is the sum total of over five different options on guaranteed pensions, which means that people's preference for 'annuity certain' is negligible. These data pertain to Chennai Division I of the Life Insurance Corporation of India.
Table 4: Figures pertaining to annuitants of individual pension policies over the last 20 years

\begin{tabular}{lrrrr}
\hline Year & OPT-A & OPT-F & Others & \multicolumn{1}{c}{ Total } \\
\hline $1988-1989$ & 0 & 2,818 & 0 & 2,818 \\
$1989-1990$ & 0 & 4,597 & 0 & 4,597 \\
$1990-1991$ & 0 & 5,169 & 0 & 5,169 \\
$1991-1992$ & 0 & 5,363 & 0 & 5,363 \\
$1992-1993$ & 0 & 1,049 & 0 & 1,049 \\
$1993-1994$ & 0 & 1,008 & 0 & 1,008 \\
$1994-1995$ & 0 & 1,102 & 0 & 1,102 \\
$1995-1996$ & 0 & 1,001 & 0 & 1,001 \\
$1996-1997$ & 0 & 1,247 & 0 & 1,247 \\
$1997-1998$ & 0 & 1,360 & 0 & 1,360 \\
$1998-1999$ & 0 & 1,723 & 0 & 1,723 \\
$1999-1900$ & 0 & 3,062 & 0 & 3,062 \\
$2000-2001$ & 115 & 2,761 & 153 & 3,029 \\
$2001-2002$ & 77 & 3,174 & 523 & 3,774 \\
$2002-2003$ & 80 & 2,521 & 384 & 2,985 \\
$2003-2004$ & 105 & 3,689 & 498 & 4,292 \\
$2004-2005$ & 266 & 6,455 & 802 & 7,523 \\
$2005-2006$ & 399 & 8,941 & 1,710 & 11,050 \\
$2006-2007$ & 371 & 8,862 & 918 & 10,151 \\
$2007-2008$ & 78 & 1,914 & 177 & 2,169 \\
& 1,491 & 67,816 & 5,165 & 74,472 \\
\hline
\end{tabular}

Year=vesting year and month; OPT A=pension for life; OPT $\mathrm{F}=$ pension for life with return of purchase price; statistics excludes Varishta pension policies (T-161) which is with option "F" only. No. of 161 pols in the zone=52,085 ('F').

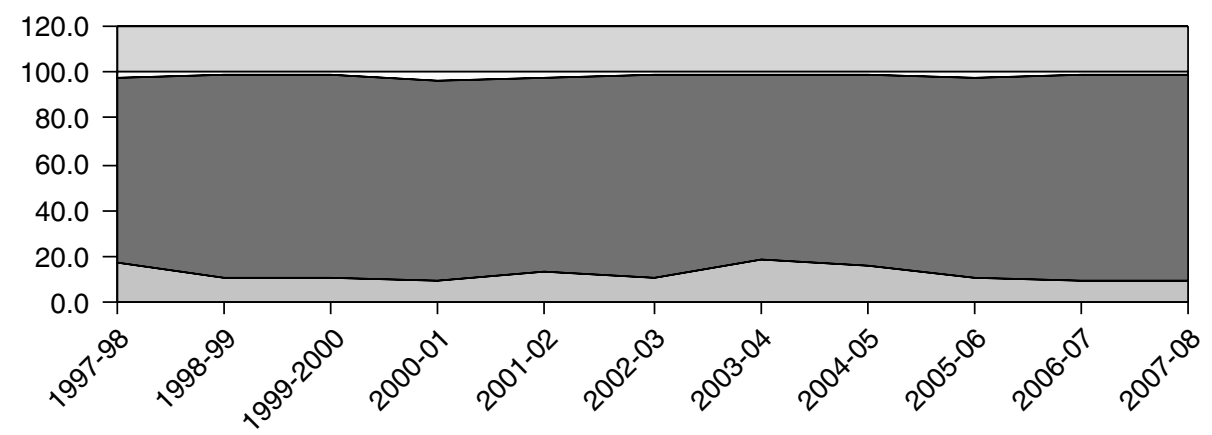

Figure 2: Table 3 in percentages

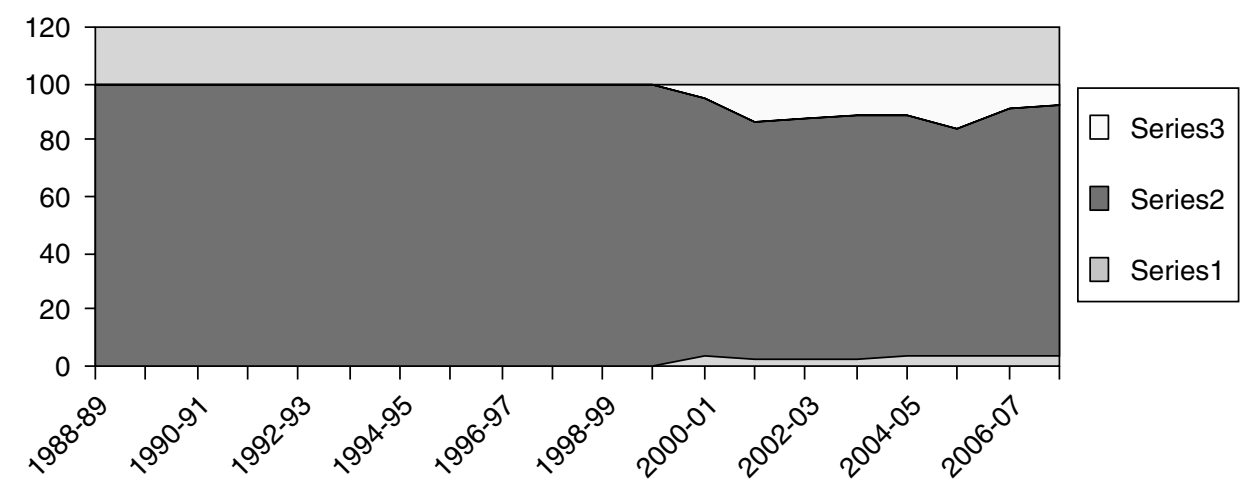

Figure 3: Series 1 represents 'life pension'. Series 2 represents 'pension with ROC. Series 3 represents all annuities-certain put together 
are studied to determine whether there is any specific trend in exercising pension options by annuitants. The figures pertain to South India and are from the Life Insurance Corporation of India (Table 4, Figure 3).

The above statistics have omitted Varishta Pension policies (Table 161), which are exclusively under option F. No other option is available under that plan. A total of 52,085 annuities exist under this plan.

The above statistics are given in percentages in Figure 3, which enable a quick comparison.

\section{Discussion}

The response of the group surveyed is given below along with comparative figures from the past:

\begin{tabular}{lccc}
\hline Preferences & $\begin{array}{l}\text { Life } \\
\text { pension } \\
(\%)\end{array}$ & $\begin{array}{l}\text { ROC } \\
(\%)\end{array}$ & $\begin{array}{l}\text { Certain } \\
\text { (guaranteed) } \\
(\%)\end{array}$ \\
\hline Survey results 2008 & 5 & 84 & 11 \\
2007-2008 (IP) & 3.6 & 88.2 & 8.2 \\
[GS] & 8.8 & 90.3 & 0.9 \\
2002-2003 (IP) & 2.7 & 84.5 & 12.9 \\
(GS) & 10.9 & 87.6 & 1.5 \\
1997-1998 (IP) & 0 & 100 & 0 \\
(GS) & 17.1 & 81 & 1.9 \\
$1992-1993$ & 0 & 100 & 0 \\
$1988-1989$ & 0 & 100 & 0 \\
\hline
\end{tabular}

Note: IP=individual pension policy; GS=group superannuation/ beneficiaries under employer-employee group superannuation schemes.

These figures show a changing preference of annuitants in India as regards various options under pensions/annuities. The preferences under individual and group policies are distinctly different. In both, the first preference is for pension for life with ROC to the nominee. This is in accordance with the government's pension pattern, where benefits are given to a dependent spouse on the death of a pensioner, and it perfectly matches the nation's cultural values. ROC on the death of an annuitant is considered as 'life cover' by annuitants. Therefore, ROC is akin to a life insurance death claim. In the survey, 84 per cent of the respondents felt it this way, and all of them considered it their duty to provide for their spouses and dependents even beyond their death. One has to admit this is a noble approach.
All annuitants preferred retirement ages prescribed by the governments, central or state, as the age at which annuity shall commence and all of them preferred monthly mode. Citizens look at pensions/annuities as a wage concept. In the case of individual pension policies, where every annuitant has to exercise his option independently, the preference was in favour of 'annuity certain'. Here again, what determines the preference is the guarantee that is available on pension/annuity for 'that many years and thereafter for life'. Obviously, if the annuitant were to die early the annuity is guaranteed for a certain number of years. The welfare of the spouse is the concern of the annuitant. The risky choice of life pension was the weakest choice of the elderly. Only those people whose spouses were earning or who had other sources of income chose life pension.

Coming to beneficiaries under employeremployee superannuation group schemes, the prevalence of peer pressure could be seen. Unlike in individual pension policies, in group schemes the pension/annuity option is exercised when one is going to retire, that is, while still in service of the employer. As is seen in any organisational situation, much deliberation takes place among peers as to what would be the best choice to go for. Family protection takes a back seat and enjoying the fruits of one's savings when one is alive gets the nod. Consequently, in group superannuation schemes annuitants prefer life pension to annuity certain.

All these are cases where annuity policies were purchased at least one generation before and annuity options too have already been exercised. The survey responses, however, give us a higher preference for life pensions and a decrease in the choice of annuities with ROC. The respondents of the survey are not near the superannuation age, and their choices will come into operation 20-30 years from now. They show a trend away from culture-related options and are more attuned to enjoying life 'here and now' without bothering about dependents' predicaments in the future. It might be a reflection of changing culture. The choices of 'options' is not having any correlation with the return on investment. For example, the coefficient of correlation between the rate of 
return on investment and various annuity options is as follows (pertains to group superannuation schemes):

- Life pension/annuity (no guarantee): (-) 0.207054603 .

- Pension/annuity certain (some guarantee on pension): 0.339147387 .

- Pension/annuity for life with ROC to nominee (full guarantee on capital): 0.211064607 .

In individual pension/annuity plans however, the coefficient of correlation between the rate of return and choice for 'Annuity for life with return of capital' is 0.916154047 .

\section{Conclusion}

Return on investment affects the sale/purchase of immediate annuity plans. All the deferred annuity plans help in building up a corpus fund, which is then used to purchase immediate annuity. Law does not allow the withdrawal of pension corpus, except for commuted value, because contributions to the corpus enjoyed special tax concessions and is set up for a specific purpose. Pension options are a function of culture and compulsions of the annuitant or the society to which he/she belongs. Persons and their dependents with other income - from landed property, rent, interest, dividend, pension from government, etc — opt for life pensions/annuities. Others prefer 'Annuity for life with return of capital'. They are ready to pay a high premium for reclaiming the capital, by way of reduction from life pension. Individual pension/annuity policy annuitants exercise annuity/pension options that answer return on investment as well as societal values. ROC is a great motivator in the pension business. 